\title{
KNOWLEDGE ABOUT COMPLICATIONS AND PRACTICE OF ABORTION AMONG FEMALE UNDERGRADUATES IN THE UNIVERSITY OF IBADAN, NIGERIA
}

\author{
E.O. Cadmus ${ }^{1}$ and E.T. Owoaje ${ }^{1}$ \\ ${ }^{1}$ Department of Community Medicine, University College Hospital, Ibadan, Nigeria
}

\author{
Correspondence: \\ Dr. Eniola O. Cadmus \\ Department of Community Medicine, \\ University College Hospital, Ibadan, \\ Nigeria \\ Email: eniyolacadmus@yahoo.co.uk.
}

\begin{abstract}
Background: Unwanted pregnancies and unsafe abortion pose major health risks to women in the reproductive age group. Female undergraduates are particularly exposed to these risks. This study was carried out to assess the knowledge about complications and practice of abortion among female undergraduates of the University of Ibadan.

Methods: A cross-sectional study was conducted using structured, self-administered questionnaires, to collect data on respondents' socio-demographic characteristics, sexual behaviour, knowledge about various complications of abortion and practice of abortion. Data was analyzed using SPSS version 14.

Results: A total of 425 students were interviewed, mean age of the undergraduates was $21.5 \pm 2.8$ years. Overall, $122(29 \%)$ of the respondents had ever had sexual intercourse. Twenty five percent of those who were sexually active had ever been pregnant and $\mathbf{9 0 \%}$ had terminated the pregnancy. The most common reason given for termination was that pregnancy was unplanned for. Most of the respondents $354(83.3 \%)$ had a good knowledge about complications of abortion and mean knowledge score was $4.01 \pm 1.58$ (range 0-5).

Conclusion: This group of students were aware of the risks associated with unsafe abortion; however, the abortion rate was still high. Sexual reproductive health interventions are needed on campus in order to equip female undergraduates with comprehensive knowledge and skills to reduce the likelihood of unplanned pregnancies
\end{abstract}

Keywords: knowledge, abortion complications, female undergraduates, Nigeria.

\section{INTRODUCTION}

Unsafe abortion has been defined by the World Health Organization as a procedure for terminating unwanted pregnancy that is performed by someone lacking the necessary skills or in an environment lacking minimal medical standards or both. ${ }^{1}$

Unsafe abortions can endanger women's reproductive health and lead to serious, often life-threatening complications. Furthermore, unsafe abortions impose a heavy burden on women and society by virtue of the serious health consequences that often ensue. In most African countries, abortion remains both unauthorized and unsafe and is a leading cause of maternal deaths accounting for a global average of $13 \%$ of pregnancy related fatalities. ${ }^{2}$ It has been documented that young adults are more likely to delay seeking termination, employ the use of unqualified and unskilled providers and also use dangerous methods to induce abortion. ${ }^{1}$ Annually, an estimated 2-4.4 million adolescents resort to abortion worldwide and a WHO estimate of unsafe abortion revealed that in the African region, youth aged between 15-24 years account for more than $50 \%$ of all abortion related mortality. ${ }^{2}$

Young adults terminate unplanned pregnancies for various reasons; these include fear of expulsion from school, unstable relationships, financial instability and lack of support from the partner. ${ }^{3}$ In cases where early marriage or single mothers are unaccepted, the pregnancy not only represents an unwanted responsibility but also the end of hope of further education, financial advancement and improved social opportunities in life. ${ }^{3}$ Young women in the university environment are away from home for the first time 
and become free to experiment sexually especially without any parental supervision. For the young females, there is usually associated coercion from older students and the liberal atmosphere of the university, which are factors that further encourage this experimentation. Coupled with their lack of, or poor knowledge of contraception, quite a few usually end up with unwanted pregnancies and are quite often faced with the predicament of dealing with the problem thereof. Few studies have however documented the knowledge about complications and practice of abortion among young women in the university environment.

Unsafe abortion is of public health concern because of its dire reproductive health consequences and impact on maternal morbidity and mortality. Tackling this problem will go a long way towards achieving one of the Millennium Developmental Goals, which aims to reduce overall maternal mortality by two thirds by the year 2015. This study therefore aimed at determining the knowledge of complications and practice of abortion among the female undergraduates in the University of Ibadan.

\section{MATERIALS AND METHODS Study Area}

The study was carried out in the University of Ibadan, located in the south western part of Nigeria; the university was founded in 1948 as Nigeria's first tertiary educational institution. The university is mainly residential. There are four halls designated for female undergraduates; three of which are located on the main campus and a clinical students' hostel, the Alexander Brown Hall which is on the grounds of the University Teaching Hospital about 5 kilometers away. The total population of female undergraduates resident on campus in the 2003/2004 session was 2, 887 .

\section{Study Design}

The study was a cross-sectional survey carried out among female undergraduates aged between 15years to 30 years, resident in the halls on the campus of the University of Ibadan.

\section{Sample size calculation}

The sample size was based on a reference prevalence value of induced abortion rate among female undergraduates in the University of Benin which reported that $34 \%$ of the sample of female undergraduates interviewed had ever terminated a pregnancy. $^{4}$
Using the sample size calculation for single proportion, ${ }^{5}$

$$
\begin{array}{rl}
\mathrm{n} & =\underline{\mathrm{N} z 2 \mathrm{pq}} \\
\text { where } \mathrm{n} & \mathrm{d} 2(\mathrm{~N}-1)+\mathrm{z} 2 \mathrm{p}(1-\mathrm{p}) \\
\mathrm{N} & =\text { minimum sample size } \\
\mathrm{z} & =\mathrm{z} \text { value }(\text { a constant corresponding } \\
& \text { to confidence level of } 90 \%)=1.65 \\
\mathrm{~d} & =\text { absolute degree of precision at } \\
& 3.5 \%=(0.35) \\
\mathrm{P} & =\text { proportion of students who had } \\
& \text { ever had an induced abortion } \\
& =0.34 \\
\mathrm{q} & =1-\mathrm{p}(0.66) \\
\mathrm{n} & =\underline{2887 \times 1.652 \times 0.34 \times 0.66} \\
& 0.352(2887-1)+1.652 \times 0.34 \times 0.66 \\
& =\quad 423
\end{array}
$$

A total of 425 respondents were however interviewed.

\section{Sampling Technique}

A systematic random sampling technique was used in this study. A sample frame consisting of the number of rooms occupied by female undergraduates resident in the halls was constructed. The sampling interval was calculated and using the simple ballot technique, the first room number was chosen. Subsequently, every 5 th room was included starting from the first room chosen. The population of each hall was considered when choosing the number of rooms to be included in the study (proportionate selection). All the occupants of the chosen rooms were interviewed.

\section{Exclusion Criteria}

Female undergraduates who were not resident on campus were excluded from the study.

\section{Pre-Testing}

The questionnaire was pre-tested among female students resident on campus in the Ibadan Polytechnic. After the pre-test, the questionnaire was revised and ambiguous questions were rephrased or where necessary excised.

\section{Data Collection}

Data was collected by the principal investigator and a research assistant. The purpose of the study was explained to the students and informed written consent was obtained from them before they were given the questionnaires to fill. Before leaving every respondent's room, the completed questionnaires were checked and if any information was missing, the questionnaire was returned to the respondents to fill. Administration of questionnaires was done in the evening between $6.00 \mathrm{pm}$ and $9.00 \mathrm{pm}$ when most students were usually found in their rooms; however during the weekends, questionnaires were also administered in the morning between 8.00 am and 12 noon. 


\section{Data management and analysis}

The open ended questions in the survey instrument were coded; data was cleaned and entered into the computer using the Statistical Package for the Social Sciences (SPSS) version 14.0. Data editing included the generation of frequency tables and the initial exploratory analysis, which ensured that categorical and numerical variables fell within plausible and permissible limits.

\section{Assessment of study variables}

\section{Knowledge of complications of abortion}

There were 5 questions testing the knowledge of the complications of abortion. The correct response to each question was given a score of one and wrong response zero; with this, knowledge scores were computed. Good knowledge was taken as score of three and above while poor knowledge was a score of less than three.

\section{RESULTS}

A total of 450 female undergraduates were approached to participate in the study but 25 refused to participate, giving a response rate of $95 \%$. The mean age of the respondents was $21.5 \pm 2.8$ years with a range of $15-30$ years. The majority, 414 (97.4\%) were single, $242(56.9 \%)$ were aged between $20-24$ years and about a third $150(35.2 \%)$ were in the first year of study. The socio-demographic characteristics of the respondents are as shown in Table 1 below.

\begin{tabular}{lrr}
\hline $\begin{array}{l}\text { Socio-demographic } \\
\text { characteristics }\end{array}$ & $\mathbf{n}$ & $\mathbf{\%}$ \\
\hline Age group (years) & & \\
$<20$ & 120 & 28.3 \\
$20-24$ & 242 & 56.9 \\
$\geq 25$ & 63 & 14.8 \\
Marital Status & & \\
Never married/Single & 414 & 97.4 \\
Married & 7 & 1.7 \\
Cohabiting & 3 & 0.7 \\
Widowed & 1 & 0.2 \\
Level of Study & & \\
100 level & 150 & 35.2 \\
200 level & 53 & 12.5 \\
300 level & 90 & 21.2 \\
400 level & 73 & 17.2 \\
500 level & 27 & 6.4 \\
600 level & 32 & 7.5 \\
Ethnic Group & & \\
Yoruba & 319 & 75.1 \\
Igbo & 65 & 15.3 \\
Hausa & 2 & 0.5 \\
Others** & 39 & 9.1 \\
\hline$*$ Other tribes include Hausa & Edo and Ijaw
\end{tabular}

$* *$ Other tribes include Hausa, Edo and Ijaw

Table 1: Socio-demographic characteristics of the respondents $(\mathrm{N}=425)$

\section{PRACTICE OF ABORTION}

One hundred and twenty two $(28.7 \%)$ of the respondents had ever had sexual intercourse. The median age at sexual debut was 19 years \pm 2.31 years (range 11-25years) and most had their sexual debut between ages $20-24$ years. Thirty $(24.5 \%)$ of the sexually active respondents had ever been pregnant with $28(93.3 \%)$ of such ending in induced abortion. Most, 17 (60.7\%) having procured abortion only once. The highest number of times an individual had an induced abortion was eight times. Often times, the procedure was done in private establishments, 27 $(96.4 \%)$ and the average cost for procuring an abortion was 4561 (range $200-35,000$ ).

Only four of the respondents who procured abortion reported post abortal complications mainly bleeding $2(50.0 \%)$ other reported complications were infection and stomach pains.

Over half $16(57.1 \%)$ of the respondents who had ever been pregnant and terminated the pregnancy said it was because they were not yet ready to bear the responsibility of having and raising a child while five $(17 \%)$ said it was because they were scared of the future consequences as shown in the Table 2.

\begin{tabular}{lrr}
\hline Outcome of pregnancy & $\mathbf{n}$ & $\mathbf{\%}$ \\
\hline Ever pregnant $(\mathbf{n}=\mathbf{3 0})$ & 30 & 24.5 \\
Yes & 92 & 75.5 \\
No & & \\
Ever had an abortion $(\mathbf{n}=\mathbf{3 0})$ & 28 & 93.3 \\
Yes & 2 & 6.7 \\
No & & \\
Number of abortions & 17 & 60.7 \\
1 & 8 & 28.5 \\
2 & 3 & 10.7 \\
$\geq 3$ & 4 & 14.3 \\
Complications of abortion $(\mathbf{n}=\mathbf{2 8})$ & \\
Yes & 24 & 85.7 \\
No & & \\
Reasons for abortion $(\mathbf{n}=\mathbf{2 8 )}$ & 18 & 64.2 \\
Not ready for responsibility & 5 & 17.9 \\
Afraid of future consequences & 2 & 7.1 \\
Parents refusal of marriage & 2 & 7.1 \\
Health reasons & 1 & 3.5 \\
No excuse & \\
Cost of abortion & 12 & 42.9 \\
$<$ N2000 & 6 & 21.4 \\
N2000-3000 & 10 & 35.7 \\
\hline N3000 & & \\
\hline &
\end{tabular}

Table 2: Proportion of respondents who had ever been pregnant and outcome of pregnancy 
KNOWLEDGE ABOUT COMPLICATIONS OF ABORTION

Three hundred and eighty-four (90.4\%) respondents knew that infertility was a complication of abortion; $363(85.4 \%)$ knew death was a possible complication; $345(81.2 \%)$ knew unsafe abortion may be associated with bleeding and $336(79.1 \%)$ and 326 (76.7\%) respectively knew that unsafe abortion may be associated with increased risk of contracting HIV/ its complications while $201(83.1 \%)$ of respondents between age $20-24$ years and $55(87.3 \%)$ of those aged 25 years and above had a good knowledge of the complications of abortion. These findings were not statistically significant $\left(\mathrm{X}^{2}=0.965 \mathrm{p}=0.617\right)$.

There was however a significant relationship between the level of study, and knowledge about complications of abortion. About three quarters 114 (76.0\%) of

\begin{tabular}{lll}
\hline Knowledge on complications of abortion & Yes (n \%) & No (n \%) \\
\hline $\begin{array}{l}\text { Aware that abortion can lead to inability to have children in } \\
\text { the future }\end{array}$ & $384(90.4)$ & $41(9.6)$ \\
Aware that unsafe abortion can lead to death & $363(85.4)$ & $62(14.6)$ \\
Aware that bleeding is a possible complication of unsafe & $345(81.2)$ & $80(18.8)$ \\
abortion. & & \\
Know there is a possibility of contracting HIV/ AIDS while & $336(79.1)$ & $89(20.9)$ \\
obtaining abortion & \\
Aware that abortion can lead to infection of the reproductive & $326(76.7)$ & $99(23.3)$ \\
tract
\end{tabular}

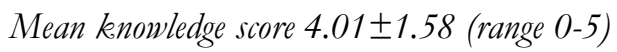

Table 3: Knowledge about complications of unsafe abortion $(n=425)$

AIDS and infection of the reproductive tract respectively. On computation of the knowledge scores, the mean knowledge score of the respondents was $4.01 \pm 1.58$ (range 0-5).

Majority of the respondents, 354 (83.3\%) had a good knowledge about the complications of abortion. Ninety- eight $(81.7 \%)$ of respondents aged less than 20 years had a good knowledge about abortion and respondents in the first year of study had a good knowledge about complications of abortion compared with $240(87.3 \%)$ of respondents in second year of study and above. Knowledge about complications of abortion was higher among those who had ever been pregnant, $27(90.0 \%)$ and ever had an abortion, $24(85.7 \%)$ compared with those who had never been pregnant 327 (82.3) or ever had an abortion $330(83.1 \%) \quad(p>0.05)$.

\begin{tabular}{|c|c|c|c|c|}
\hline \multirow{2}{*}{$\begin{array}{l}\text { Respondents } \\
\text { Characteristic }\end{array}$} & \multicolumn{2}{|c|}{ Knowledge about complications } & \multirow[t]{2}{*}{$\mathbf{X}^{2}$} & \multirow[t]{2}{*}{$\mathrm{p}$ value } \\
\hline & $\begin{array}{l}\text { Good } \\
\mathrm{n}(\%)\end{array}$ & $\begin{array}{l}\text { Poor } \\
\mathrm{n}(\%)\end{array}$ & & \\
\hline \multicolumn{5}{|l|}{ Age Group } \\
\hline$<20$ years & $91(75.8)$ & $29(24.2)$ & & \\
\hline $20-24$ years & $187(77.3)$ & $55(22.7)$ & & \\
\hline$>=25$ years & $52(82.5)$ & 11(17.5) & 1.116 & 0.617 \\
\hline \multicolumn{5}{|l|}{ Level of study } \\
\hline 100 level & $114(76.0)$ & $36(24.0)$ & & \\
\hline$\geq 200$ level & $240(87.3)$ & $35(12.7)$ & 8.86 & 0.03 \\
\hline \multicolumn{5}{|l|}{ Ever had sex } \\
\hline Yes & $95(77.9)$ & $27(22.1)$ & & \\
\hline No & $259(85.5)$ & $44(14.5)$ & 3.62 & 0.041 \\
\hline \multicolumn{5}{|c|}{ Ever Pregnant $(n=122)$} \\
\hline Yes & $27(90.0)$ & $3(10.0)$ & & \\
\hline No & $327(82.3)$ & $68(17.2)$ & 1.043 & 0.228 \\
\hline
\end{tabular}

Table 4: Knowledge about complications of abortion by respondents social and reproductive health characteristics. $(\mathrm{N}=425)$ 


\section{DISCUSSION}

This study assessed the knowledge and practice of abortion among female undergraduates in the University of Ibadan. Among the sexually active, about a third experienced unwanted pregnancies most of which ended in termination. This figure is higher than what was reported by Arowojolu et al in their survey among Nigerian undergraduates where slightly less than one fifth of their respondents that had ever been pregnant had an abortion. ${ }^{6}$ On the other hand, a study conducted among female undergraduates in the University of Benin revealed a slightly higher prevalence and about one third of the females had ever had an abortion. ${ }^{4}$

Also, majority of the respondents in the study who had ever had an abortion were in the youngest age group. Other studies have documented that the majority of women who procure abortion are usually young and unmarried. ${ }^{3,5}$ This may be because most times they have poor knowledge and access to contraception leading to unplanned and unwanted pregnancies. ${ }^{3}$ Furthermore, in many African societies, single motherhood is frowned upon and in the event that the father of the child is not willing to take up the responsibility for the child, the young female is more often faced with the problems of dealing with the pregnancy and termination seems to be the easiest way out of the predicament. ${ }^{5}$

In many instances, adolescents terminate pregnancies for various reasons including fear of expulsion from school, denial by spouse and failed contraception. ${ }^{3}$ The commonest reason given by the respondents in this study for terminating the unwanted pregnancy was unpreparedness for child bearing. Other reasons given included young age and fear of future consequences as the female might not be able to complete her studies. Similar findings were observed by other researchers. ${ }^{3,7}$

Only four of the respondents in the study who had ever had an abortion experienced complications mainly haemorrhage and infection. Mitsunaga et al in their review of risk factors for complications of abortion in south western Nigeria identified haemorrhage among the common post abortal complication amongst patients seen. ${ }^{8}$ However, other studies identified sepsis as the commonest post abortal complication. ${ }^{9-11}$

In conclusion, this study has yielded considerable insight into the knowledge of complications and practice of abortion among female undergraduates in the University of Ibadan.
Most of the respondents had a good knowledge about abortion and its complications. However almost all the respondents who had ever been pregnant terminated the pregnancy despite the knowledge of the possible complications. Sexually active respondents should be encouraged to adopt methods of prevention of unwanted pregnancy.

\section{Acknowledgements}

We are grateful to the field staff for their assistance with this study and Dr. Simbo Ige for reviewing the manuscript.

\section{REFERENCES}

1. World Health Organization. The prevention and management of Unsafe Abortion. Geneva: World Health Organisation 1992.

2. World Health Organization editor. Unsafe Abortion: Global and Regional Estimates of the Incidence of Unsafe Abortion and Associated Mortality in 2000. 4th ed. Geneva: World Health Organisation; 2004.

3. Olukoya P. Reducing Maternal mortality from unsafe abortion among Adolescents in Africa Afr J Reprod Health. 2004;8(1):57-62.

4. Aziken ME, Okonta PI, Ande AB. Knowledge and perception of emergency contraception among female Nigerian undergraduates. Int Fam Plan Perspect. 2003;29(2):84-87.

5. Olukoya A, Kaya A, Ferguson B, AbouZahr C. Unsafe abortion in adolescents. Int J Gynaecol Obstet. 2001;75:137-147.

6. Arowojolu AO, Ilesanmi AO, Roberts OA, Okunola MA. Sexuality, contraceptive choice and AIDS awareness among Nigerian undergraduates. Afr J Reprod Health. 2002;6(2):60-70.

7. Moodley J, Akinsooto VS. Unsafe Abortions in a developing country: Has Liberalization laws on Abortion made a difference? Afr J Reprod Health 2003;7(2):34-38.

8. Mitsunaga T, Larsen U, Okonofua F. Risk Factors for Complications of Induced Abortions in Nigeria. J Womens Health. 2005;14(6):515-28.

9. Ladipo OA. Preventing and managing complications of induced abortion in Third World countries. Int J Gynecol Obstet. 1989;suppl. 3:2128.

10. Emuveyan E, Agboghoroma O. Trends in Abortion Related Maternal Mortality in Lagos Nigeria. TJOG. 1997;14(1).

11. Ogunniyi SO, Makinde OO, Dare FO. Abortion-related deaths in Ile-Ife, Nigeria: A 12year review. Afr J Med Med Sci. 1990;19(4):271274 